\title{
Effect of Spun Velocities and Composition on the Microstructure and Transformation Temperatures of TiNi Shape Memory Ribbons
}

\author{
Enrique López Cuellara, Luis López Pavón ${ }^{a}$, Esaú Nuñez Mendozaa , Carlos José De Araújo \\ Walman Benicio De Castro ${ }^{b}$, Cezar Gonzalez ${ }^{c}$, Jorge Otubo ${ }^{d}$
}

\author{
${ }^{a}$ Centro de Investigación Innovación y Desarrollo en Ingeniería y Tecnología - CIIDIT, Facultad de \\ Ingeniería Mecánica y Eléctrica - FIME, Universidad Autónoma de Nuevo León-UANL, parque PIIT \\ km. 10 autopista al Aeropuerto Internacional de Monterrey, Apódaca, N.L., México \\ ${ }^{b}$ Universidade Federal de Campina Grande - UFCG, Av. Aprigio Veloso, 882, Bairro Universitário, \\ C.P. 10069, Campina Grande, PB, Brazil \\ ${ }^{c}$ Universidade Federal de Pernambuco - UFPE, Av. Acadêmico Hélio Ramos, s/n, Cidade Universitária, \\ Recife, PE, Brazil \\ ${ }^{d}$ Instituto Tecnológico de Aeronáutica - ITA, Praça Marechal Eduardo Gomes, 50, CEP 12228-900, São \\ José dos Campos, SP, Brazil
}

Received: June 30, 2015; Revised: June 28, 2016; Accepted: August 10, 2016

\begin{abstract}
Ti-50.13Ni and Ti-49.62 Ni (at.\%) shape memory alloy ribbons were fabricated by melt-spinning method at different circumferential wheel velocities. The effects of wheel velocity, chemical composition and heat treatments on microstructure and Transformation temperature were investigated. Differences in wheel velocity led to differences in cooling rate and sample dimension, as well as in phase transformation temperatures. Two heat treatment conditions were studied, $350^{\circ} \mathrm{C}$ for $1 \mathrm{~h}$ and $350^{\circ} \mathrm{C}$ for $5 \mathrm{~h}$. In the samples produced at high wheel velocity and heat-treated at $350^{\circ} \mathrm{C}$ for $5 \mathrm{~h}$, nanosized Ti-rich precipitates were observed in both chemical compositions. Cross-sectional microstructure was studied by optical microscopy; SEM was used to study the nanometric grains and nano precipitation. The transformation temperatures were analyzed by DSC.
\end{abstract}

Keywords: Ti-Ni Shape memory alloys Ribbons, Melt-spinning process, Ti rich nanoprecipitate, Transformation temperature

\section{Introduction}

Among all the shape memory alloys (SMAs), the near equiatomic TiNi alloy is one of the most used due to the their excellent properties like corrosion resistance, biocompatibility and its superior mechanical properties such as large deformation and recovery force ${ }^{1,2}$. In addition, TiNi thin films show shape memory effects comparable to those of bulk materials ${ }^{2,3}$. TiNi ribbons manufactured by melt-spinning technique have demonstrated to be easily manufactured having control over chemical composition and can be manufactured with less than $20 \mu \mathrm{m}$ thick. TiNibased ribbons have attracted much attention because of their potential applications on microactuators such as microvalves, micropumps and microgrippers. These devices are considered part of the micro-electro-mechanical systems $(\mathrm{MEMS})^{4-7}$. Furthermore and despite that the ribbons are thicker than the thin film, it is known that grain size of the ribbons produced by melt-spinning are reduced to nanoscale and along with the rapid solidification, the shape memory properties can be obtained in the ribbons even without further heat treatments ${ }^{8}$.

The microstructure of the melt-spun ribbons depend on values of different parameters such as wheel speed, gas

\footnotetext{
* e-mail: lpavon07@gmail.com
}

pressure, melt temperature and nozzle-wheel gap. In this study two different TiNi ribbons were fabricated by the meltspinning method with wheel velocities of $30 \mathrm{~m} / \mathrm{s}$ and $50 \mathrm{~m} / \mathrm{s}$, and the relation between the wheel speed and microstructure were analyzed by optical and scanning electron microscopy. The effects on transformation temperature were analyzed by DSC, showing in this case, that $\mathrm{R}$ phase transformation temperature can be measured using the slope change on the curves of percent phase transformation vs. temperature.

\section{Experimental Section}

The conventional vacuum induction melting (VIM) process was employed to elaborate binary Ti-Ni SMAs. The buttons had a nominal composition of Ti-50.13Ni and Ti-49.62Ni (at.\%), hereafter called M1 and M2, respectively. Their transformation temperatures obtained by DSC are presented in Table 1. After that, the buttons were placed in a melt-spun equipment to produce the ribbons.

The melt-spun ribbons were produced under a $200 \mathrm{mbar}$ argon atmosphere using a quartz crucible with a nozzle diameter of $1.0 \mathrm{~mm}$; the melt was ejected onto the surface of a polished copper wheel having a tangential wheel speed 
Table 1: Phase transformation temperatures of the row materials ${ }^{\mathrm{a}}$.

\begin{tabular}{lcccc}
\hline Alloy & As $\left({ }^{\circ} \mathrm{C}\right)$ & $\mathrm{Af}\left({ }^{\circ} \mathrm{C}\right)$ & $\mathrm{Ms}\left({ }^{\circ} \mathrm{C}\right)$ & $\mathrm{Mf}\left({ }^{\circ} \mathrm{C}\right)$ \\
\hline M1 & 58.0 & 77.9 & 49.7 & 34.9 \\
M2 & 67.6 & 87.8 & 59.3 & 44.0
\end{tabular}

${ }^{a}$ Grade $1 \mathrm{Ti}, 99.80$ wt.\% purity (balance); electrolytic Ni, 99.95 wt. $\%$ purity.

fixed at 30 and $50 \mathrm{~m} / \mathrm{s}$. The distance between the nozzle and the copper wheel was $0.5 \mathrm{~mm}$; the thickness average of the ribbons varied from 30 up to $50 \mu \mathrm{m}$, depending on the casting parameter, for example higher linear velocity produces smaller thickness 9 . In order to decrease in defects like dislocations, which are generated during melt-spinning, the samples were heat treated at $350^{\circ} \mathrm{C}$ for 1 and 5 hours. Table 2 shows some characteristics of the obtained ribbons, focusing on the chemical composition measured by energy dispersive X-ray (EDX) to corroborate the composition initially used in the VIM process. As can be seen EDX results was very close to the initial composition.

Differential Scanning Calorimetry (DSC) was employed to determine the martensitic transformation temperatures of the produced $\mathrm{Ti}-\mathrm{Ni}$ ribbons for all conditions. The measurement was carried out by a DSC model Q20 of TA Instruments (temperature accuracy $\pm 0.1^{\circ} \mathrm{C}$ ), in a temperature range from $120^{\circ} \mathrm{C}$ to $-40^{\circ} \mathrm{C}$ and cooling/ heating rate controlled at $5^{\circ} \mathrm{C} / \mathrm{min}$. In order to analyze the microstructural changes due to the wheel velocities and heat treatments, a Nikon FX-35WA optical microscopy was used. Furthermore, a FEI Nova NanoSEM 200 scanning electronic microscopy was used for a better understanding of the effects on the microstructure.

\section{Results and Discussion}

\subsection{Effects of wheel velocities and heat treatment on microstructure}

The Figure 1 shows the optical micrographs of the transversal section of the as-spun specimens. The contact
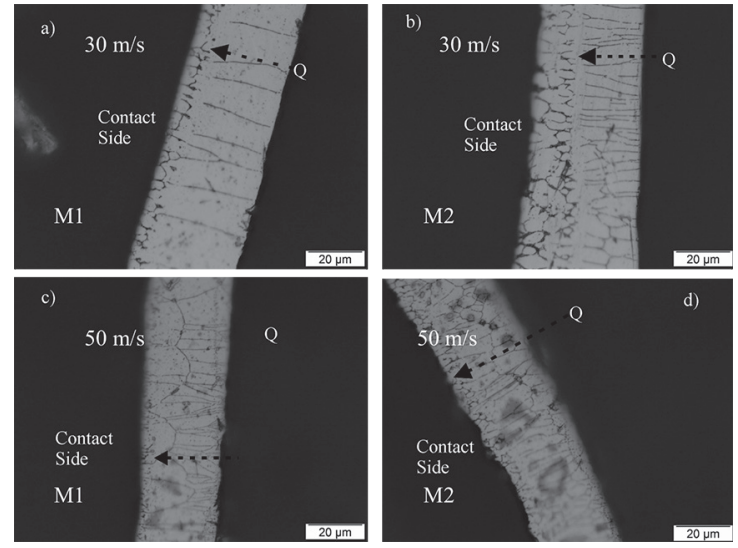

Figure 1: Optical micrograph for specimen manufactured at 30 $\mathrm{m} / \mathrm{s}$ a) $\mathrm{M} 1$ and b) M2. For specimen manufactured at $50 \mathrm{~m} / \mathrm{s} \mathrm{c}$ ) M1 And d) M2.

side is indicated in the figure. This side consists in very fine equiaxed grains. On other hand, as we move to the right on the image, well defined columnar grains grew from the equiaxed grains in opposite direction of heat flux (Q), see Figure $1 \mathrm{a}$ and $1 \mathrm{~b}$ for $\mathrm{M} 1$ and $\mathrm{M} 2$, respectively, at $30 \mathrm{~m} / \mathrm{s}$. In the Figure $1 \mathrm{c}$ and $1 \mathrm{~d}$ the specimens manufactured at 50 $\mathrm{m} / \mathrm{s}$ are shown respectively for M1 and M2, showing the same behavior, but as it was expected, the specimens were thinner due to the higher velocity of the wheel, which means quicker solidification, more defects and smaller grains than grains of samples at $30 \mathrm{~m} / \mathrm{s}$.

Now, another interesting phenomenon takes place in the contact zone, in M1 smaller grains were developed than in M2, but in the noncontact zone bigger grain size were observed in $\mathrm{M} 1$ in both conditions, concerning to the wheel velocity. I.e. the sample rich in $\mathrm{Ni}$ or M1, promotes a more heterogeneous microstructure between the contact and no contact zone, along with the heterogeneity a lot of defects are present due to the rapid cooling velocities, which means a bigger difference between the temperature of the beginning and the end of transformation and also in properties. For this reason heat treatments were carried out.

Table 2: Thermal and chemical characteristics of the obtained ribbons

\begin{tabular}{|c|c|c|c|c|c|c|c|}
\hline \multirow{2}{*}{ Alloys } & \multirow{2}{*}{$\begin{array}{c}\text { Tangential } \\
\text { Wheel } \\
\text { Speed, m/s }\end{array}$} & \multirow{2}{*}{ HT-1 } & \multicolumn{2}{|c|}{ EDX } & \multirow[t]{2}{*}{ HT-2 } & \multicolumn{2}{|c|}{ EDX } \\
\hline & & & $\mathrm{Ti}$ (at \%) & $\mathrm{Ni}($ at $\%)$ & & Ti (at \%) & $\mathrm{Ni}$ (at \%) \\
\hline \multirow{2}{*}{ M1 } & 30 & $350^{\circ} \mathrm{C}$ & 49.7 & 50.3 & $350^{\circ} \mathrm{C}$ & 49.3 & 50.7 \\
\hline & 50 & $1 \mathrm{~h}$ & 49.1 & 50.9 & $5 \mathrm{~h}$ & 49.7 & 50.3 \\
\hline \multirow{3}{*}{ M2 } & 30 & $350^{\circ} \mathrm{C}$ & 50.6 & 49.4 & $350^{\circ} \mathrm{C}$ & 51.0 & 49.0 \\
\hline & & & & & & & \\
\hline & 50 & $1 \mathrm{~h}$ & 50.4 & 49.6 & $5 \mathrm{~h}$ & 50.2 & 49.8 \\
\hline
\end{tabular}


Figure 2 shows the SEM micrographs of the contact zone from heat-treated $\mathrm{M} 1$ and $\mathrm{M} 2$ ribbons at $350^{\circ} \mathrm{C}$ for $5 \mathrm{~h}$ manufactured at $30 \mathrm{~m} / \mathrm{s} \mathrm{a}$ ) and b) and at $50 \mathrm{~m} / \mathrm{s} \mathrm{c}$ ) and d) respectively. The grain size for M1 after the heat treatment in Figure $2 \mathrm{a}$ is around $1 \mu \mathrm{m}$ and in Figure $2 \mathrm{~b}$ for $\mathrm{M} 2$ is around $2 \mu \mathrm{m}$, confirming that the sample rich in $\mathrm{Ni}$ in the contact zone favors the formation of small grains. And also this was the reason why in Figure 1, it was difficult to observe by optic microscope the grains of the contact zone for both as spun samples. In Figure $2 \mathrm{c}$ and $2 \mathrm{~d}$, manufactured at $50 \mathrm{~m} / \mathrm{s}$, well-defined nanosize grains $(<100 \mathrm{~nm})$ can be observed for both specimens. This kind of microstructure retards the martensitic transformation and diminishes the strain recovery due to the large amount of grain boundaries that imposes constraints to the martensitic transformation. As it was already mentioned, the grain size is smaller as consequence of the higher wheel velocity, attributed to the higher cooling rate that allows a faster nucleation and growth process.
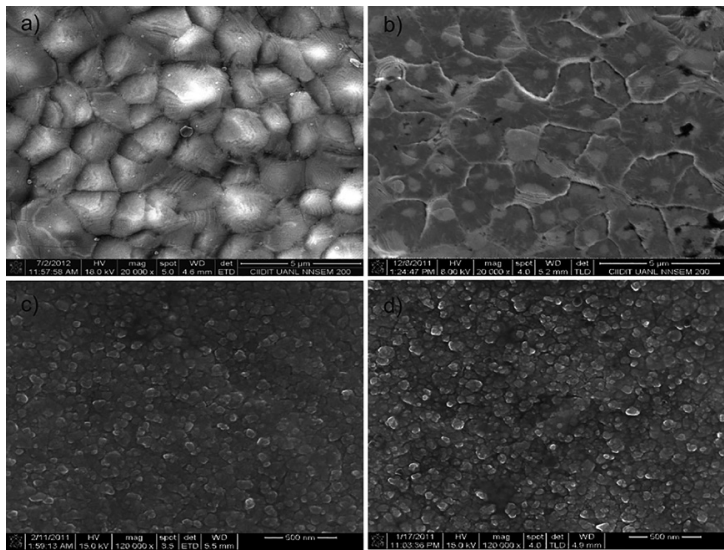

Figure 2: SEM micrograph for specimens heat treated at $350^{\circ} \mathrm{C}$ for $5 \mathrm{~h}$ manufactured at $30 \mathrm{~m} / \mathrm{s}$ a) M1 and b) M2 and at $50 \mathrm{~m} / \mathrm{s} \mathrm{c}$ ) M1 and d) M2.

Some defects as dendritic growths were found, which favors the nucleation and growth of pre-martensitic $\mathrm{R}$ phase $^{10}$ (Figure 3a). Moreover, at higher wheel velocity very high strain energy is stored during the process, favoring the precipitation of fine, nanometric Ti-rich particles. The Figures $3 \mathrm{~d}$ shows these nanoparticles precipitated in grain boundaries; it is important to notice that no matter the former composition, at this velocity Ti-rich precipitates were found in both specimens.

\subsection{Effects of wheel velocities and heat treatment on transformation temperature}

Figure 4 shows the DSC curves for the melt-spun Ti-Ni ribbons at 30 and $50 \mathrm{~m} / \mathrm{s}$ corresponding to $\mathrm{M} 1$ and $\mathrm{M} 2$ alloys which were annealed at $\mathrm{HT}-1\left(350^{\circ} \mathrm{C}\right.$ for $\left.1 \mathrm{~h}\right)$ and $\mathrm{HT}-2\left(350^{\circ} \mathrm{C}\right.$ for $5 \mathrm{~h}$ ), as well as, as-spun condition for comparison purposes. The start and finish temperatures of the phase transformation

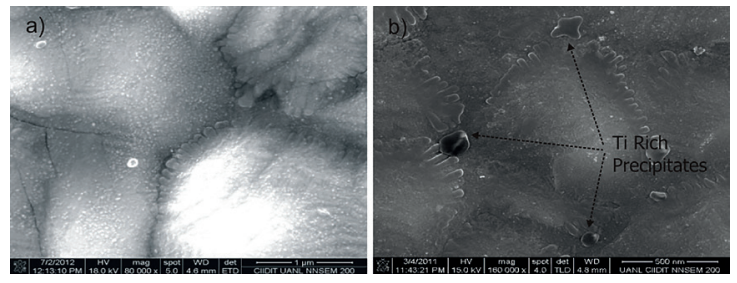

Figure 3: SEM micrograph showing defects as dendritic growth a) and b) Ti rich precipitates.
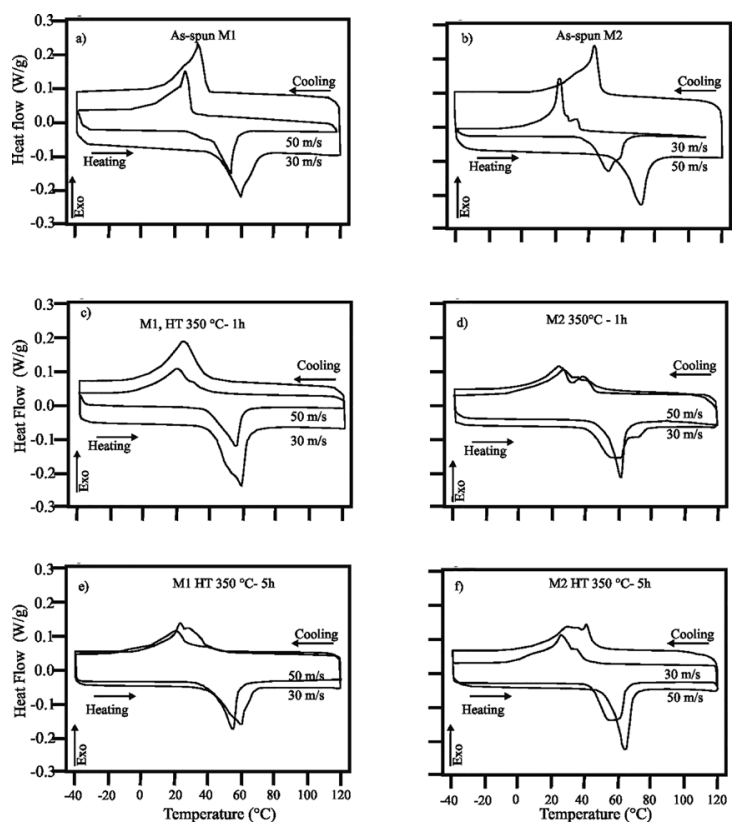

Figure 4: DSC results corresponding to the as-spun (a-b) and annealed ribbons at HT-1 and HT-2, (c-d) M1 and (e-f) M2.

were determined by the inception of the slope change in the DSC curves. Figure $4 a-b$ represents the as-spun states for M1 and $\mathrm{M} 2$ respectively. In the Figure $4 \mathrm{a}$, it can be seen that the transformation temperatures (TTRs) decreased with increasing of the tangential velocity for M1 Ni-rich alloy, and this is in accordance with some references ${ }^{11-13}$, which has been attributed to the fact that if speed increases the cooling rate increased, leading to a decrease in grain size and therefore in TTRs. An opposite behavior was observed for Figure $4 \mathrm{~b}$. For this later case, the phenomenon has been attributed to the Ti content ${ }^{14}$. As it was observed, all conditions including the as-spun ribbons, present the reversible austenite $\leftrightarrow$ martensite transformation.

Also, in general DSC curves with broad transformation temperature range and complex shape can be observed on cooling, mainly for heat-treated samples. The complexity is attributed to the well-known two-stage martensitic phase transformation $\mathrm{B} 2 \rightarrow \mathrm{R} \rightarrow \mathrm{B} 19^{\prime}$. Clearly, after the heat treatments, the conditions that seemed to present a single transformation peak, now begin to split into two, this fact can be observed for most conditions. As was shown in microstructure section, the large number of grain boundaries and Ti-rich precipitates 
were found when the specimen were manufactured at high wheel velocity, as a result an additional energy is required to complete the martensitic transformation, this leading to lower the transformation temperature, as observed on DSC results.

However, because of their shape, it is complicated to determine exactly the finish of the $\mathrm{R}-$ phase $\left(\mathrm{R}_{\mathrm{f}}\right)$ temperature transformation and the start of $\mathrm{B} 19^{\prime}$ martensitic transformation $\left(M_{s}\right)$ for ribbons fabricated at lowest wheel speed. Due to the complications, to determinate the R-phase temperature from the DSC curves, the percent phase transformation as function of temperature was plotted to determinate the transformation temperatures using the change in slope.

The Figures 5 and 6 show the transformation hysteresis of the M1 and M2 specimen, respectively. The transformation temperatures were taken from the forward transformation where the slope changed. Transformation temperatures are indicated by an arrow. In the case of the M1 specimen, the effect of wheel velocity on transformation temperature can be followed in the as-spun specimen; Figures $5 \mathrm{a}$ and $5 \mathrm{~b}$ correspond to the samples manufactured at velocities of 30 and $50 \mathrm{~m} / \mathrm{s}$ respectively. The hysteresis increased when the velocity increased. In contrast the temperature transformation decreased, for instance $\mathrm{Ms}$ decreased about $7.5^{\circ} \mathrm{C}$. Also the Rs decreased, this is due to the decreased in grain size ${ }^{15}$. Heat treatment effect on transformation temperatures was in the same direction, i.e. the transformation temperatures decreased in heat-treated sampled. For the M1 specimen manufactured at $30 \mathrm{~m} / \mathrm{s}$, the slope change was neglected and the $\mathrm{R} f$ and $\mathrm{M} s$ could not be determined, for that reason only $\mathrm{R} s$ and $\mathrm{M} f$ are marked, see Figure $5 \mathrm{c}$ and $5 \mathrm{~d}$. For the specimen at $50 \mathrm{~m} / \mathrm{s}$ the HT1 had more effect on Rs than the $\mathrm{Ms}$ and hysteresis grew in more than $2{ }^{\circ} \mathrm{C}$. The hysteresis decreased for M1specimen treated for $5 \mathrm{~h}$ and for the M2 the effect on the $\mathrm{H}_{T}$ was negligible.

The transformation temperatures for M2 specimen were different due to the changes in chemical composition and concerning to the wheel speed opposite behavior was observed, see Figure 6. The TTRs decreased with increases the wheel velocity. This was attributed to the higher Ti content ${ }^{15}$.

For better understanding, the effect of the spun velocity on the transformation temperatures is summarized in Table 3 . As the wheel velocity increases from 30 to $50 \mathrm{~m} / \mathrm{s}$, a decreased in the transformation temperatures can be observed. For each case, the enthalpy of transformation decreased as well, in concordance with a previous work ${ }^{16}$. This can be attributed to the high cooling rate, causing a reduction of the grain size and increasing structural defects, such as dislocations. The presence of these defects lowers the $M f$ temperature. In addition, in high energy process as melt spinning where $\mathrm{Ti}-\mathrm{Ni}$ alloys are highly deformed, the dislocations formed a net in the region close to the grain boundaries; thus, the TTRs decrease and the transformation occur in two stages, as can be seen in Figure 4 and previously reported by Goryczka, $\mathrm{T}^{12}$.

Finally, it is important to mention that the transformation temperatures were calculated from graphics of martensite (\%) vs
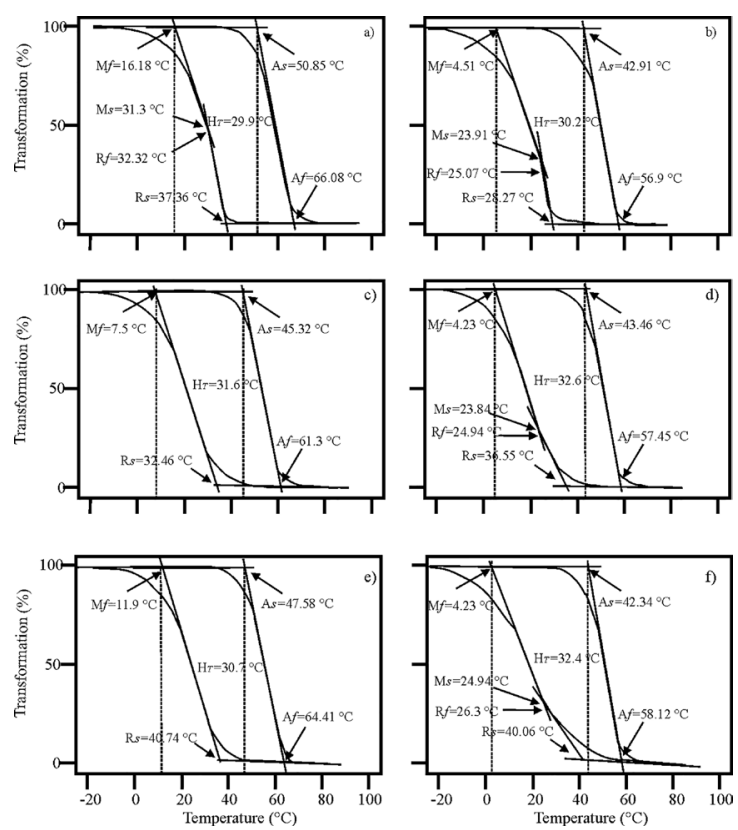

Figure 5: Transformation hysteresis for $\mathrm{M} 1$ as-spun specimen a) 30 $\mathrm{m} / \mathrm{s}$, b) $50 \mathrm{~m} / \mathrm{s}$. Heat treated at $350{ }^{\circ} \mathrm{C}$ for $1 \mathrm{~h} \mathrm{c}$ ) $30 \mathrm{~m} / \mathrm{s}$, d) $50 \mathrm{~m} / \mathrm{s}$ And Heat treated at $350{ }^{\circ} \mathrm{C}$ for $5 \mathrm{~h} \mathrm{e)} 30 \mathrm{~m} / \mathrm{s}$, f) $50 \mathrm{~m} / \mathrm{s}$.
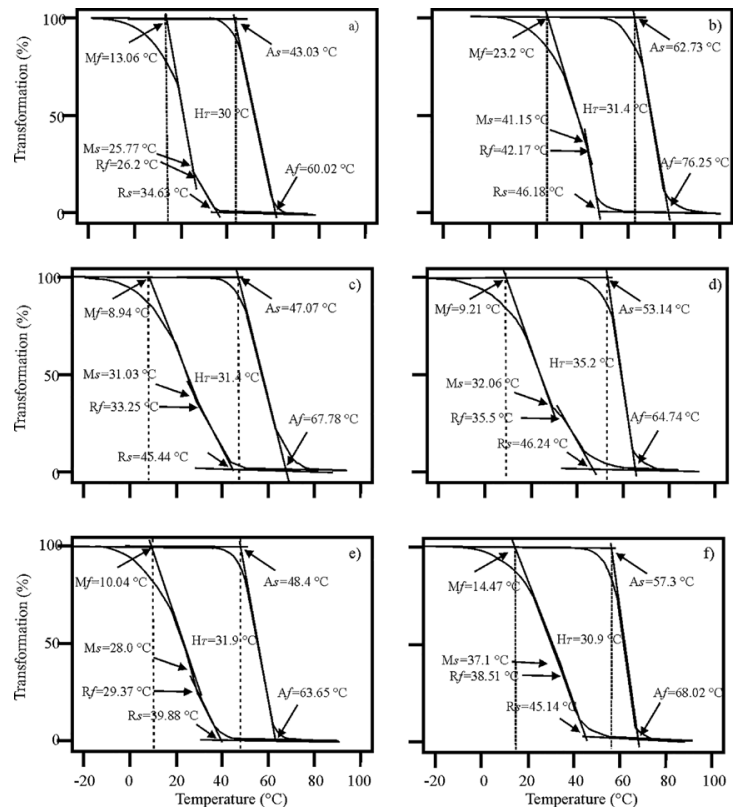

Figure 6: Transformation hysteresis for $\mathrm{M} 2$ as-spun specimen a) 30 $\mathrm{m} / \mathrm{s}$, b) $50 \mathrm{~m} / \mathrm{s}$. Heat treated at $350{ }^{\circ} \mathrm{C}$ for $1 \mathrm{~h} \mathrm{c}$ ) $30 \mathrm{~m} / \mathrm{s}$, d) $50 \mathrm{~m} / \mathrm{s}$. And Heat treated at $350{ }^{\circ} \mathrm{C}$ for $5 \mathrm{~h}$ e) $30 \mathrm{~m} / \mathrm{s}$, f) $50 \mathrm{~m} / \mathrm{s}$.

temperature, the results confirm that one of the most important factors to take into account for melt spinning is the wheel speed.

\section{Conclusions}

Effects of wheel velocity on microstructure and transformation temperatures of two different composition shape memory 
Table 3: The values of transformation temperatures $\left({ }^{\circ} \mathrm{C}\right)$ and enthalpy changes $(\mathrm{J} / \mathrm{g})$ of forward and reverse martensitic transformation for Ti-Ni SMA ribbons at different annealing and wheel velocity.

\begin{tabular}{lccccccccc}
\hline $\begin{array}{l}\text { Type of } \\
\text { Ribbon }\end{array}$ & $\begin{array}{c}\text { Wheel } \\
\text { speed } \\
(\mathrm{m} / \mathrm{s})\end{array}$ & $R_{s}$ & $R_{f}$ & $M_{s}$ & $M_{f}$ & $A_{s}$ & $A_{f}$ & $\Delta H A \rightarrow M$ & $\Delta H M \rightarrow A$ \\
\hline as-spun: & 30 & 37.36 & 32.32 & 31.30 & 16.18 & 50.85 & 66.08 & 24.62 & 21.89 \\
M1 & 50 & 28.27 & 25.07 & 23.91 & 4.51 & 42.91 & 56.90 & 21.56 & 18.22 \\
HT-1: & 30 & 32.46 & - & - & 7.50 & 45.32 & 61.30 & 24.61 & 23.54 \\
M1 & 50 & 36.55 & 24.94 & 23.84 & 4.23 & 43.46 & 57.45 & 20.82 & 19.43 \\
HT-2: & 30 & 40.74 & 33.86 & 31.88 & 11.90 & 47.58 & 64.41 & 22.17 & 20.12 \\
M1 & 50 & 40.06 & 26.30 & 24.94 & 2.86 & 42.34 & 58.12 & 21.32 & 19.87 \\
as-spun: & 30 & 34.63 & 26.20 & 25.77 & 13.06 & 43.03 & 60.02 & 24.00 & 19.31 \\
M2 & 50 & 46.18 & 42.17 & 41.15 & 23.20 & 62.73 & 76.25 & 21.06 & 19.37 \\
HT-1: & 30 & 45.44 & - & - & 8.94 & 47.06 & 67.78 & 23.91 & 22.34 \\
M2 & 50 & 46.24 & 35.50 & 32.03 & 9.21 & 53.14 & 64.74 & 23.23 & 18.56 \\
HT-2: & 30 & 39.88 & 29.37 & 28.00 & 10.04 & 48.40 & 63.65 & 22.64 & 20.05 \\
M2 & 50 & 45.14 & 38.51 & 37.10 & 14.47 & 57.30 & 68.02 & 26.68 & 22.78 \\
\hline & & & & & & & & &
\end{tabular}

ribbons were analyzed. The ribbons showed a heterogeneous microstructure between de contact and noncontact zone. Samples rich in Ni promote this heterogeneity. The results showed that with increasing the wheel velocity, the ribbons were thinner and with smaller grain size. At wheel velocity of $30 \mathrm{~m} / \mathrm{s}$ and after the heat treatment, bigger grain sized were showed for both samples and they showed defects as dendritic growth, than can promote nucleation and growth of pre-martensitic R phase. Based on the result, at higher wheel velocity thinner ribbons with nanosized grain can be obtained.

\section{Acknowledgments}

This work was also supported by the project 107462 and 219535 from CONACYT.

\section{References}

1. Otsuka K, Ren X. Recent developments in the research of shape memory alloys. Intermetallics. 1999;7(5):511-528.
2. Miyazaki S, Ishida A. Martensitic transformation and shape memory behavior in sputter deposited TiNi-base thin films. Materials Science and Engineering: A. 1999;273-275:106-133.

3. Fu YQ, Du HJ, Huang WM, Zhang S, Hu M. TiNi-based thin films in MEMS applications: a review. Sensors and Actuators A: Physical. 2004;112(2-3):395-408.

4. Tomozawa M, Kim HY, Miyazaki S. Shape memory behavior and internal structure of Ti-Ni-Cu shape memory alloy thin films and their application for microactuators. Acta Materialia. 2009;57(2):441-452.

5. Kim YW, Kim HJ, Nam TH. Effect of annealing conditions on microstructures and shape memory characteristics of $\mathrm{Ti}_{50}-$ $\mathrm{Ni}_{30}-\mathrm{Cu}_{20}$ alloy ribbons. Journal of Alloys and Compounds. 2008;449(1-2):134-138.

6. Nam TH, Kim WY. Shape memory characteristics of rapidly solidified $\mathrm{Ti}_{50} \mathrm{Ni}_{15} \mathrm{Cu}_{35}$ alloy ribbons. Intermetallics. 2010;18(10):1946-1949.

7. Xu D, Wang L, Ding G, Zhou Y, Yu A, Cai B. Characteristics and fabrication of NiTi/Si diaphragm micropump. Sensors and Actuators A: Physical. 2001;93(1):87-92.

8. Crone WC, Wu D, Perepezko JH. Pseudoelastic behavior of nickel-titanium melt-spun ribbon. Materials Science and Engineering: A. 2004;375-377:1177-1181. 
9. Mehrabi K, Bruncko M, McKay BJ, Kneissl AC. Influence of quenching rates on equiatomic NiTi ribbons fabricated by melt-spinning. Journal of Materials Engineering and Performance. 2009;18(5):475-478.

10. Nam TH, Kim JK, Choi MS, Kim YW, Im HJ, Ahn JS, et al. R phase transformation in equiatomic TiNi alloy ribbons fabricated by rapid solidification. Journal of Materials Science Letters. 2002;21(9):685-688.

11. Lara-Rodriguez GA, Gonzalez G, Flores-Zúñiga H, CortésPérez J. The effect of rapid solidification and grain size on the transformation temperatures of $\mathrm{Cu}-\mathrm{Al}-\mathrm{Be}$ melt spun alloys. Materials Characterization. 2006;57(3):154-159.

12. Goryczka T. Effect of wheel velocity on texture formation and shape memory in $\mathrm{Cu}-\mathrm{Al}-\mathrm{Ni}$ based melt-spun ribbons. Archive of Metallurgy and Materials. 2009;54(3):755-763.
13. Frenzel J, George EP, Dlouhy A, Somsen CH, Wagner MFX, Eggeler G. Influence of $\mathrm{Ni}$ on martensitic phase transformations in NiTi shape memory alloys. Acta Materialia. 2010;58(9):3444-3458

14. Balak Z, Abbasi SM. Influence of the Ti content, training cycles and pre-strain on the two-way shape memory effect in NiTi alloys. Materials \& Design. 2011;32(7):3992-3996.

15. Pan G, Cao Z, Wei M, Shi S, Xu L, Meng X. Thickness and grain size dependence of $\mathrm{B} 2-\mathrm{R}$ martensitic transformation behaviors in nanoscale TiNi films. Materials Letters. 2014; $130: 285-288$.

16. Lin KN, Wu SK. Martensitic transformation of grain-size mixed $\mathrm{Ti}_{51} \mathrm{Ni}_{49}$ melt-spun ribbons. Journal of Alloys and Compounds. 2006;424(1-2):171-175. 